\title{
Soil Moisture and Dendrometer Sampling of Kent Trees Irrigated with Micro-Sprinklers
}

\author{
Federico Hahn* \\ Irrigation Department, Universidad Autonoma Chapingo, México \\ *Corresponding author: Federico Hahn, Irrigation Department, Universidad Autonoma Chapingo, Texcoco, México. \\ To Cite This Article: Federico Hahn. Soil Moisture and Dendrometer Sampling of Kent Trees Irrigated with Micro-Sprinklers. Am J Biomed Sci \\ \& Res. 2021 - 13(6). AJBSR.MS.ID.001940. DOI: 10.34297/AJBSR.2021.13.001940.
}

Received: 眥 August 18, 2021; Published: 眥 August 24, 2021

\begin{abstract}
Mexico is the leading mango exporter worldwide and requires to optimize yield; quality and water use. Water shortage due to climatic changes can affect yield production and quality by increasing fruit drop and size. In the period 2018-2020 decrease in raining events reduced mango yields. Sustained deficit irrigation (SDI) techniques have been applied worldwide and four holes were dig to wet each tree by means of a micro-sprinkler irrigation system. Soil moisture content around the trees were acquired and compared against those irrigated all around the tree trunk. Also dendrometer measurements at the branches help to understand water dynamics within the tree; and high yields were obtained when branches had good water uptake. It was found that roots are closer to the surface and that dry soil areas beneath branches did not provided enough water to produce mangoes over 350 grams.
\end{abstract}

Keywords: Dendrometer; Soil Moisture Monitoring; Mango Trees; Yield; Micro-Sprinkler Wetting Area

\section{Introduction}

Mango [1] is an important tropical fruit worldwide, being in 2019 the sixth most produced (56 million tonne year ${ }^{-1}$ ) in the world after bananas, apples and grapes [2]. Mexico with a production of 8.98 $\mathrm{MT} \mathrm{ha}^{-1}$, is the first mango exporter in the world. More than 110,000 farmers in Mexico use organic practices [3] to produce their mango world demand with varieties that include Kent, Keitt, Haden and Ataulfo. Although is some places along the Mexican littoral there are two productions along the year, in other areas, fruit development takes place within March and June. Trees are very sensible to water stress during fruit growth, being water supply critical during the first six weeks of the fruit development process to ensure high yields and good quality [4]. Drought induces late-stage fruit drop as well as a reduction in fruit mass. The latter is caused by a decline in cell size and number [5]. Rain is scarce during the fruiting season, so research has been carried out to find irrigation techniques that can help to optimize water use.

Sustained deficit irrigation (SDI) applies water as a fraction of the potential evapotranspiration of a well-watered reference crop, without affecting drastically its yield [6]. The average yield for trees under a $50 \%$ SDI was $20 \%$ lower than the productivity obtained from non-stressed trees (100\% ETC). Total amount of sugars was also reduced with deficit irrigation [7]. Water use efficiency (WUE) is significantly higher in deficit irrigation treatments than with daily irrigation scheduling [8]. Automatic irrigation systems turn-on micro-sprinklers when the soil water content reaches a minimum threshold [9]. PRD (partial root zone) and SDI have been employed for irrigation scheduling of fruit trees with the outcome of sensors.

Micro-sprinkler irrigation effectively reduces water consumption and increases crop yields [9]. Micro sprinklers are desirable because fewer heads are required to cover a large area. Micro-sprinkler distribution is not always uniform, being several variables that reduce its efficiency [10]. An increase in fruit yield with irrigation is due to a lower fruit drop rather than to have bigger fruits (Spreer et al., 2009). Recovery time of a micro-irrigation system takes less than 5 years, being PRD (partial root zone) irrigation the most economical one [11]. In this paper both soil water content and water uptake in the tree branches was studied 
to see the effect of zone irrigation in fruit yield. Dendrometers measured leaf uptake in branches, and soil moisture sensors the water in the soil area beneath the canopy.

\section{Materials and Methods}

The experiment was carried out during the year 2021 in a mango orchard located in Loma Bonita, Guerrero (17 25 '47 "N, $-101^{\circ} 11^{\prime} 19^{\prime \prime} \mathrm{W}, 17 \mathrm{~m}$ ASL). The apparent density of the red loam clay soil was obtained from 30 random samples, being its average density of $1.1 \mathrm{gcm}^{-3}$. The samples were extracted from holes at depths between 10 and $40 \mathrm{~cm}$. Twenty mature 'Kent' trees with similar pruning and fertilization practices were selected for the experiment. Half of the trees were irrigated with a hose and the other ten with a micro-sprinkler system.

The low energy micro-sprinkler system provided a discharge of $120 \mathrm{l} \mathrm{h}^{-1}$, and used a low pressure of $5 \mathrm{~kg} \mathrm{~cm}^{-2}$. A wetting circular area with a radius of $1 \mathrm{~m}$ is always found after spraying (Figure 1 a, $1 \mathrm{~b}, 1 \mathrm{c}$ ), but if the soil is compact the water will evaporate easily. With a 10 -cm drill bit driven by a gasoline engine, holes $10-\mathrm{cm}$ deep were made. The holes were filled with coarse gravel, allowing the water from the sprinklers to run down towards the roots. Water was applied for half an hour every two days, providing 200 liters per tree every event. The same water was applied with a hose.
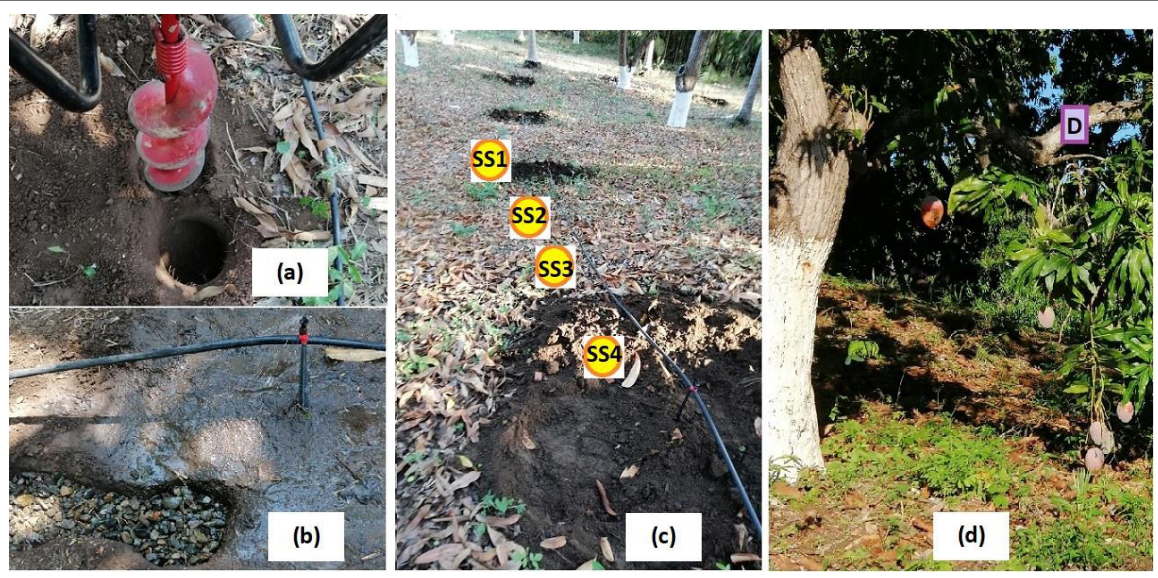

Figure 1: Mango orchard showing (a) equipment for digging holes, (b) holes filled with gravel, (c) moisture sensor SS location, and (d) dendrometer $\mathrm{D}$ placement in tree branch.

Volumetric content of water in soil was monitored with FC-28 soil moisture sensors connected to a microcontroller. Each sensor is introduced within a PVC tube and introduced to the soil at a depth of $30 \mathrm{~cm}$. It can be seen that four sensors were placed by the side of the lateral hose, being $3.33 \mathrm{~m}$ apart; tree trunks are spaced 10 meters. Although irrigation was carried out every 2 days' moisture measurements can provide an optimum threshold. A homemade linear resistor dendrometer built at the Universidad Autonoma Chapingo was at the branches one meter over the soil moisture sensors. The linear resistance sensor (model 9605R1.7KL2.0, BEISensors, USA) was attached to the branch using a stainless steel holder and the values were acquired by a microcontroller board every 30 -s intervals and averaged every 5 min.

\section{Results and Discussion}

In both (Figures $2 \& 3$ ), measurements of one tree with microsprinkler control are shown; Monitoring with hose irrigation are not shown. Trees were irrigated reaching a field capacity of $25 \%$ volumetric soil water content (VSWC) at a depth of $30 \mathrm{~cm}$. There were some events of rain during May 2021, so all the sensors measured a VSWC of $25 \%$, and irrigation was suspended for 5 days and reached $10 \%$. After irrigation was applied again the 15th of May 2021, SS1 and SS4 regained field capacity (Figure 2). This values correspond to the ones reported in Irvin mango trees [12]. At lower depth than $10 \mathrm{~cm}$, water losses were found due to atmosphere demands and root absorption [13]. The first micro sprinkler didn't turn on the 28th of May so the water soil content decreased more. The place where both sensors SS2 and SS3 were placed didn't receive water from the irrigation system. Soil water content became of $15 \%$ on May 30th for SS2 (Figure 2), but leaves in the top did not wilt, as they got water from the humid air during sunrise. Mangifera indica L. does not grow, leaves wilt and fell-off after a severe drought stress. Relative soil water content has to be maintained over $45 \%$ in soil to ensure tree normal growth and photosynthesis [1].

Internal water stored in branches were obtained with dendrometers and both monitored contractions from 8:30 until midday. Water recharge occurred in the afternoon (Figure 3). Two point dendrometers were attached to two branches, one over the wet zone and the other in a branch leaving in the dry soil. The former in yellow had a better water movement, so when the rain event occurred the branch grew as well as mango fruits. After this period, irrigation took place and the well-watered branch 
contraction-expansion had an average of $0.12 \mathrm{~mm}$ every day (Figure 3 ). Average growth of the branch over the dry soil was of $0.6 \mathrm{~mm}$, showing still some water intake from the main stem. This branch had only 5 mango fruit and their weight had an average of $250 \mathrm{~g}$ meanwhile the well-watered branch had 32 mango fruits with an average weight of $355 \pm 14$ grams. The trees with hoses provided an average of 150 fruits with $450 \pm 23$ grams each.

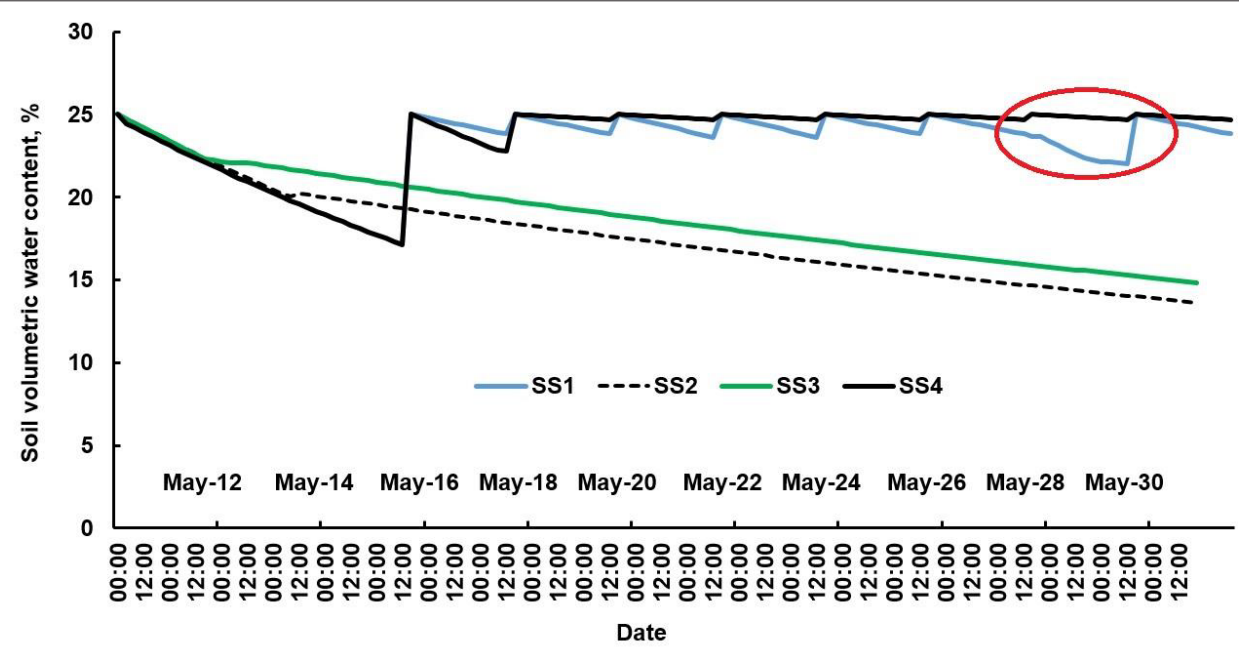

Figure 2: Soil volumetric water content measured by the sensors (SS1, SS2, SS3, SS4) during the month of May.

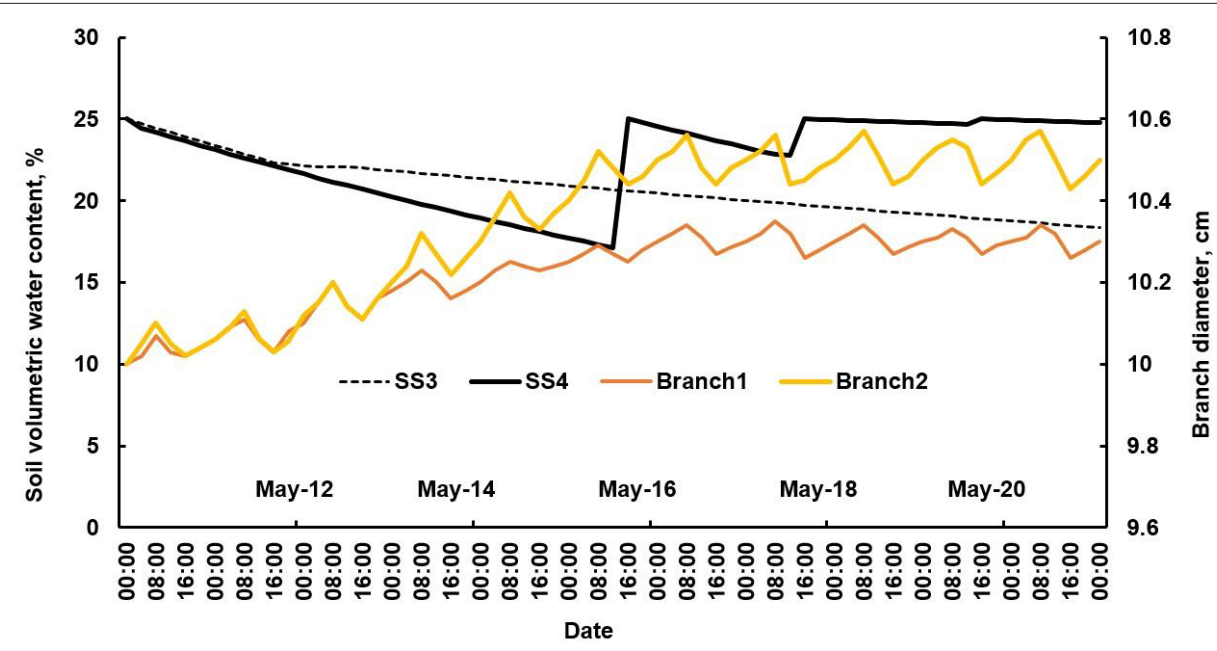

Figure 3: Soil volumetric water content measured by the sensors SS3 and SS4 and branches diameter variations sampled with dendrometers.

Different studies have been conducted to investigate tree water use in drylands after monitoring stem water content with dielectric capacitance sensors, and dielectric ECH2O moisture probes drilled within the soil at different depths [14]. Daily variation in stem water content of trees caused by transpiration or stem storage was too small to be detected by the GS3 probe [14]. Diurnal patterns of sap flow follow a similar pattern at the base of the trunk and in branches, increasing in the morning and decreasing in the afternoon $[15,16]$. A lag between the stem volumetric water content reduction and stem contraction exists and was caused by the relatively rigid tissue and water movement from the bark to the xylem [17].

\section{Conclusions}

It can be concluded from this experiment that water should be applied in all the circumference beneath the tree canopy, so that it is available for excellent yields. A better water management requires of more micro-sprinklers. The holes with gravel provided a deeper water movement, but roots are superficial. This is the reason why the leaves on the dry-zone branch did not wilt.

\section{Acknowledgements}

I will like to thank the DGIP who funded the project 21013-DTT65. 


\section{References}

1. Li YL, Liu XG, Hao K, Yang QL, Yang XQ, et al. (2019) Light-response curve of photosynthesis and model fitting in leaves of Mangifera indica under different soil water conditions. Photosynthetica 57(3): 796-803.

2. (2021) Food and Agriculture Organization of the United Nations. Worldwide Fruit Production. (FAOSTAT).

3. (2016) Alberts Organics. Organic Produce from Mexico.

4. Liu ZT, Luo GX, Wang J, Chen YQ (2007) Effects of water on the growth and fruit quality of mango. J. China Tropical Agriculture 1: 32-33.

5. Singh Z (2005) Embryo abortion in relation to fruit size, quality, and concentrations of nutrients in skin and pulp of mango. J. Plant Nutr 28: 1723-1737.

6. Durán-Zuazo V, Rodriguez C, Franco Tarifa D (2011) Impact of sustaineddeficit irrigation on tree growth, mineral nutrition, fruit yield and quality of mango in Spain. Fruits 66(4): 257-268.

7. Lipan L, Carbonell AA, Cárceles B, Durán VH, Franco Tarifa D, García, et al. (2021) Can Sustained Deficit Irrigation Save Water and Meet the Quality Characteristics of Mango? Agriculture 11(5): 448.

8. Santos M, Mauro A, Donato S, Coelho E (2014) 'Tommy Atkins' mango yield and photosynthesis under water deficit in semiarid region of Bahia Revista Brasileira de Engenharia Agrícola e Ambiental 18(9): 899-997.

9. Wei J, Liu G, Liu D, Chen Y (2017) Influence of irrigation during the growth stage on yield and quality in mango (Mangifera indica L). PLoS ONE 12(4): e0174498.

10. Koumanov K, Hopmans J, Schwankl L (2005) Spatial and temporal distribution of root water uptake of an almond tree under microsprinkler irrigation. Irrigation Science 24: 267-278.
11. Satienperakul K, Spreer W, Manochai V, Ongprasert S, Müller J (2009) Economic evaluation of different irrigation regimes in mango production in northern Thailand. Acta Horticulturae. 831: 293-300.

12. Lu P, Chacko EK (2000) Effect of water stress on mango flowering in low latitude tropics of Northern Australia. Proceedings of the Sixth International Symposium on Mango, ActaHortic 509: 283-289.

13. Vera J, Conejero W, Conesa MR, Ruiz-Sánchez MC (2019) Irrigation Factor Approach Based on Soil Water Content: A Nectarine Orchard Case Study. Water 11(3): 1-15.

14. Saito T, Yasuda H, Sakurai M, Acharya K, Sueki S, et al. (2016). Monitoring of Stem Water Content of Native and Invasive Trees in Arid Environments Using GS3 Soil Moisture Sensors. Vadose Zone Journal 15(3): 1-9.

15. Scholz F, Bucci S, Goldstein G, Meinzer F, Franco A, et al. (2008) Temporal dynamics of stem expansion and contraction in savanna trees: Withdrawal and recharge of stored water. Tree physiology 28(3): 46980 .

16. Spreer W, Ongprasert S, Hegele M, Wünsche JN, Müller J (2009) Yield and fruit development in mango (Mangifera indica, L., cv. Chok Anan) under different irrigation regimes. Agricultural Water Management 96(4): 574-584.

17. Carrasco L, Bucci S, di Francescantonio D, Lezcano O, Campanello P, et al. (2015). Water storage dynamics in the main stem of subtropical tree species differing in wood density, growth rate and life history traits. Tree physiology 35(4): 354-365. 